\title{
Do fluxo do sangue aos cortes da vida em reserva: sangue, ritual e intervenção entre as mulheres Kaiowa e Guarani em $\mathrm{MS}^{1}$
}

\author{
From blood flow to cuts of life in reservation: blood, ritual, \\ and intervention among Kaiowa and Guarani women in MS
}

Lauriene Seraguza ${ }^{2}$

DOI: http://dx.doi.org/10.20435/tellus.v17i33.444

\begin{abstract}
Resumo: Neste artigo, pretendo abordar a circulação de substâncias, com ênfase no sangue (tuguy), entre as mulheres kaiowa e guarani em Mato Grosso do Sul. Com essa abordagem, é possível pensar uma rede de relações que compõe o corpo e a pessoa kaiowa e guarani, a partir da menstruação como um marcador etário na vida das mulheres e suas relações com as intervenções do Estado. Para isto, valho-me de duas experiências etnográficas. A primeira trata-se de um ritual de primeira menstruação de uma menina kaiowa que pude acompanhar na Terra indígena Panambizinho em Dourados, MS, em 2014; a segunda refere-se a dois acompanhamentos de que participei, enquanto indigenista na Fundação Nacional do Índio (FUNAI), de acolhimento arbitrário de crianças indígenas, um na Reserva de Dourados e outro em Panambizinho. Um dos acompanhamentos tratava-se de uma situação específica em que o estatuto geracional pós-menarca foi questionado pelo Estado, contrariando o discurso dos envolvidos. Dessa forma, a partir da reflexão junto a outros dados etnográficos, etnografias sobre os Kaiowa, Guarani e Mbya e reflexões sobre redes e relações entre os ameríndios, busco analisar essas situações etnográficas apresentadas e colocá-las em conexão para pensar ritual, intervenção e os conhecimentos mobilizados sobre o sangue como caminho para o "feixe de relações" que é o corpo e a pessoa kaiowa e guarani.
\end{abstract}

Palavras-chave: sangue; mulheres Kaiowa e Guarani; ritual; redes de relação; intervenção.

Abstract: In this article I intend to approach the circulation of substances, with emphasis on blood (tuguy), between Kaiowa and Guarani women in Mato Grosso do Sul. With this approach it is possible to think of a network of relationships that

\footnotetext{
${ }^{1}$ Este artigo foi inspirado pelo curso Redes e Relações Ameríndias, ministrado pela Profa. Dominique T. Gallois, no PPGAS/USP, em 2016, e teve uma primeira versão dos dados apresentada no I Seminário de Políticas Etnográficas em Pesquisas Indígenas na mesa "Etnologia Indígena, indigenismo e sentidos da etnografia", na FCH/UFGD, 2016. Agradeço as contribuições e observações elaboradas nestas ocasiões.

${ }^{2}$ Universidade de São Paulo (USP), São Paulo, Brasil.
}

Tellus, Campo Grande, MS, ano 17, n. 33, p. 139-162, maio/ago. 2017 
make up the body and the person Kaiowa and Guarani, from menstruation as an age marker in the lives of women and their relationships with state interventions. For this, I draw on two ethnographic experiences. The first is a first menstruation ritual of a Kaiowa girl I was able to follow in Panambizinho indigenous land in Dourados, MS in 2014, the second refers to two accompaniments that I participated as an indianist in the National Indian Foundation (FUNAI) of arbitrary reception of indigenous children, one in the Dourados Reserve and the other in Panambizinho. One of the accompaniments was a specific situation where the post-menarche, the generational status was questioned by the state, contradicting the discourse of those involved. Thus, from the reflection along with other ethnographic data, ethnographies on the Kaiowa, Guarani and Mbya and reflections on networks and relations among Amerindians, I try to analyze these presented ethnographic situations and put them in connection to think ritual, intervention and the knowledge mobilized about the blood as a way to the "bundle of relations" that is the body and the person Kaiowa and Guarani.

Key words: blood; Kaiowa and Guarani women; ritual; relationship networks; intervention.

Neste texto, parto de duas experiências etnográficas vivenciadas junto aos Kaiowa e Guarani, em Mato Grosso do Sul, bastante distintas para pensar ritual, intervenção do Estado e sangue, a partir de uma reflexão sobre os modos de saberes e modos de circulação de pessoas e corpos. A primeira experiência está problematizada a partir da descrição de um convite recebido por uma rezadora kaiowa de uma terra indígena demarcada em virtude de reivindicação indígena em 2005, conhecida como Panambizinho, em Dourados, MS, para acompanhar um ritual de primeira menstruação. A segunda experiência traz uma descrição de um acompanhamento realizado em virtude de minha atuação enquanto indigenista junto à FUNAI (2014-2015) na Reserva Indígena de Dourados, MS, numa situação específica na qual o estatuto geracional pós-menarca foi questionado pelo Estado, à revelia do discurso dos envolvidos.

A distinção das localidades é fundamental na percepção dos dados aqui tratados. A Reserva de Dourados, criada pelo Estado em 1917, junto a sete outras áreas de reservas construídas em MS, entre 1915 e 1928, pelo Serviço de Proteção aos Índios (SPI), possibilita modos distintos de vida frente aos modos observados nas terras indígenas recuperadas. Essas recuperações ou retomadas de terra em MS foram delimitadas a partir dos anos 90, como resultado das reivindicações indígenas ${ }^{3}$. Esses modos de vidas serão aqui analisados a partir dos rituais realizados e dedicados ao

\footnotetext{
${ }^{3}$ É preciso ressaltar que a primeira reivindicação de terra pelos Guarani e Kaiowa em MS foi registrada pela FUNAI em 1976 (FUNAI, 1984).
} 
sangue, seu controle e excesso e sua consequente mudança de estatuto geracional dentro da parentela.

A diferença entre a vida em reserva e a vida na terra indígena recuperada perpassa pela total transformação da paisagem: as 16 mil pessoas, guarani, kaiowa e terena, que vivem na reserva de Dourados se contrastam drasticamente com as menos de 500 que vivem em Panambizinho, por exemplo, onde a composição familiar ainda não tem as marcas indeléveis, mas possui outras marcas tão profundas, de desfragmentação que o Estado e a vida em reserva proporcionaram historicamente aos coletivos guarani e kaiowa em MS. Dessa forma, a manutenção de recursos naturais, da realização de rituais dedicados ao corpo e à pessoa, são muito mais possíveis nas áreas onde o Estado pouco, ou menos, intervém, posto que fora da Reserva, a tendência é manter os núcleos familiares unidos pela parentalidade, consanguínea ou afim, marcada pela solidariedade difusa.

Não se trata, portanto, de colocar em comparação os dois contextos etnográficos, mas de refletir a partir das experiências apresentadas, os rituais dedicados ao corpo e à pessoa, ao controle do sangue entre os Kaiowa e Guarani e a possibilidade de percebê-los como "marcadores etários" (LÉVI-STRAUSS, 2010, p. 29) na vida, em especial das mulheres. Parto da hipótese de que onde o ritual não pode ser mais realizado, ou respeitado, como na vida em Reserva, o Estado intervém nos modos e relações mais íntimos da organização social dos coletivos em questão.

\section{DOS FLUXOS DO SANGUE}

Numa noite de novembro de 2014, meu celular tocou, e uma Ñandesy ${ }^{4}$, uma rezadora kaiowa de Panambizinho, foi enfática comigo ao atender a ligação: "estou ligando para avisar que minha neta está guardada", referindo-se que a menina estava reclusa em virtude do ritual de primeira menstruação. Entre os Kaiowa, ocorre a nomeação do ritual de primeira menstruação como mitã kuña ikoty ñemondy'a ou huguy guejy (AQUINO, 2017; LOPES, 2016) e, entre os Guarani, de ikuña tai e imba'e jehu (VERA, 2017). Para os Kaiowa, a situação de kuñatai é posterior à primeira menstruação, é o fato de a menina tornar-se mulher após a menarca.

A Ñandesy relatou que já iniciara o ikoty ñemondy'a, pois já tinha cortado o cabelo, e, se eu quisesse vir para acompanhar a "saída dela", "tirar foto", era para eu ir

\footnotetext{
${ }^{4}$ Conhecida na literatura antropológica como xamã.
} 
até o final da semana, quando sairiam e a levariam até a casa de reza de um Ñanderu, um rezador local. Respondi imediatamente (e feliz, pois não conseguira acompanhar o ritual durante a pesquisa de campo do mestrado) que iria no dia seguinte.

Ao chegar na casa da rezadora, a mãe da menina contou que, na sexta-feira anterior ao nosso encontro, entre quatro e cinco da manhã, ela acordou, olhou para mãe e, ao ser questionada se não iria a escola, disse que não, confirmando as expectativas da mãe de que havia menstruado. A mãe pediu para que ela ficasse em silêncio a partir de então e a chamou para cortar o cabelo. Era preciso a permanência em silêncio para que depois, "não ficasse com a boca aberta", para o resto da vida, pois os modos como a mulher procede durante a primeira menstruação, o que aprende no resguardo, são os modos que a pessoa irá proceder no decorrer da vida. Entre os Palikur, Artionka Capiberibe chama a atenção para uma memória corporal, em que o corpo relembra o conhecimento que é inscrito no corpo no decorrer da vida, pois "trata-se de uma sociedade amazônica cuja ontologia tem no corpo sua baliza central na percepção do mundo" (CAPIBERIBE, 2015, p. 188).

Isto pode sugerir que os aprendizados realizados durante o resguardo da primeira menstruação também são inscritos no corpo e podem ser rememorados durante a vida da mulher kaiowa e guarani, pois trata-se de um conhecimento relacionado ao modo de ser e viver entre esses indígenas. A mãe da menina em resguardo contou que cortou o cabelo dela com a tesoura e somente com apoio dos dedos até que a Nãndesy chegou para dar continuidade e encaminhar o ritual, pois possuía esse conhecimento devido à experiência, ou seja, a partir de sua memória corporal adquirida com os anos vivenciados. Solicitou ao marido (avô da menina) para buscar remédio no brejo, buscou folhas e lascas do tronco de cedro e regulou a alimentação da menina para comer somente arroz sem sal.

No entorno da janela do quarto onde a menina estava guardada, havia cedro preso entre as madeiras para protegê-la de cobras cegas, jaguarete (onças), jara (donos e mestres), jasy jatere ${ }^{5}$, mba'etirõ (maus espíritos) e outros animais e seres sociais que pudessem se aproximar em virtude do odor que a mulher exala neste período (pyti 'u), atrativo a esses seres. A mãe contou que, desde abril, a dieta da menina já estava mais controlada, em virtude das transformações corporais, como o crescimento do peito e que desde então, só comia carne branca, como peixe e frango, carnes consideradas frias, percebidas com menor concentração de sangue.

\footnotetext{
${ }^{5}$ Ver Seraguza (2013).
} 
Durante o resguardo, a única carne que a menina poderia consumir era a de um peixinho pequeno, de rabo vermelho, (pikytĩ). $\mathrm{O}$ avô estava pescando quando cheguei e estavam todas ansiosas pelo retorno dele da pescaria, e também, para saber se ele havia conseguido pescar o peixinho que a menina poderia comer. Durante esses meses na escola, a menina só comia bolacha de sal, e a dieta dela foi combinada entre os pais e os professores da escola, que, nessa aldeia, estão preparados para recepcionar as meninas neste estado.

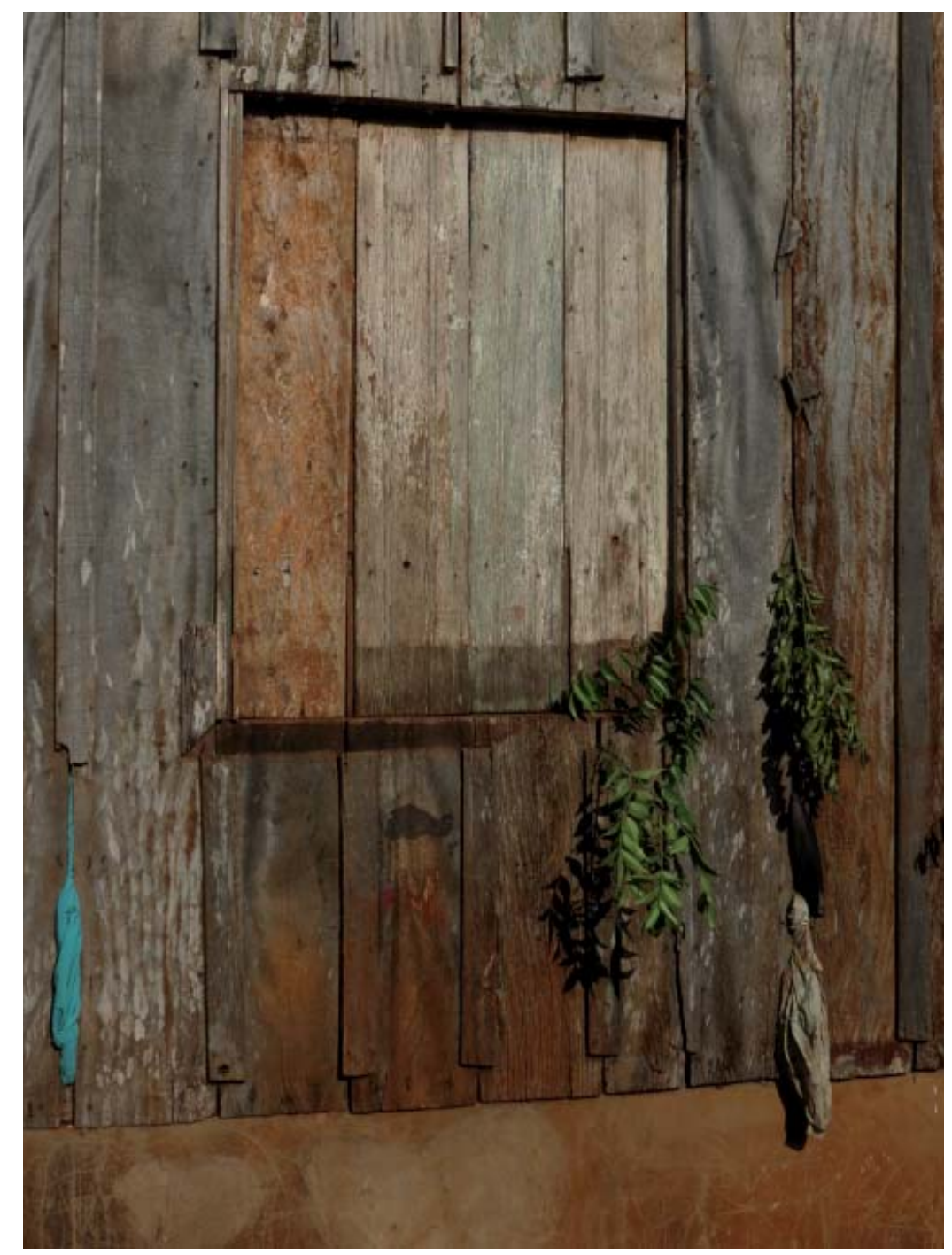

Foto 1- Reclusão, Panambizinho, MS, novembro de 2014 (Lauriene Seraguza) 
A mãe da menina contou que, quando cortava o cabelo dela, todas as crianças do entorno, primos e irmãos, ficaram em volta olhando. Os mais jovens não entediam porque a prima estava cortando o cabelo e porque não respondia mais nada para eles, permanecendo em silêncio e depois do corte de cabelo, não a viram mais. Perguntavam pela prima, irmã e não tinham respostas da família.

A menina estava "guardada" no quarto, com uma panela específica para se alimentar, colher e copo separados. Comia sozinha, não podia dormir de dia e estava sob supervisão da mãe e da avó. Quando precisava sair para ir ao banheiro ou tomar banho, era feito com a companhia da mãe que a cobria com um tecido. O banho é acompanhado de remédios do mato. Ninguém, humano ou não, poderia percebê-la naquele estado até que o ritual fosse concluído. Com os banhos profiláticos, o cheiro que a mulher exala e a sua própria presença é minimizada, o que garante a segurança do corpo e da pessoa kaiowa e guarani. Ao adentrar a casa, vi a menina num quarto escuro, com a cama cercada por roupas estendidas num varal, como numa cabana, com sua panelinha, em silêncio, sentada no meio da cama. A mãe me explicou que ela ficaria guardada por cinco dias, e no quinto dia, ela sairia coberta e iria para a casa de reza do Ñanderu para que ele rezasse e cantasse para ela, pois, depois do resguardo, iria ser igual ao nascimento, "ela nasce de novo", e assim o foi. Todas as mulheres dessa parentela passaram por esse ritual. 


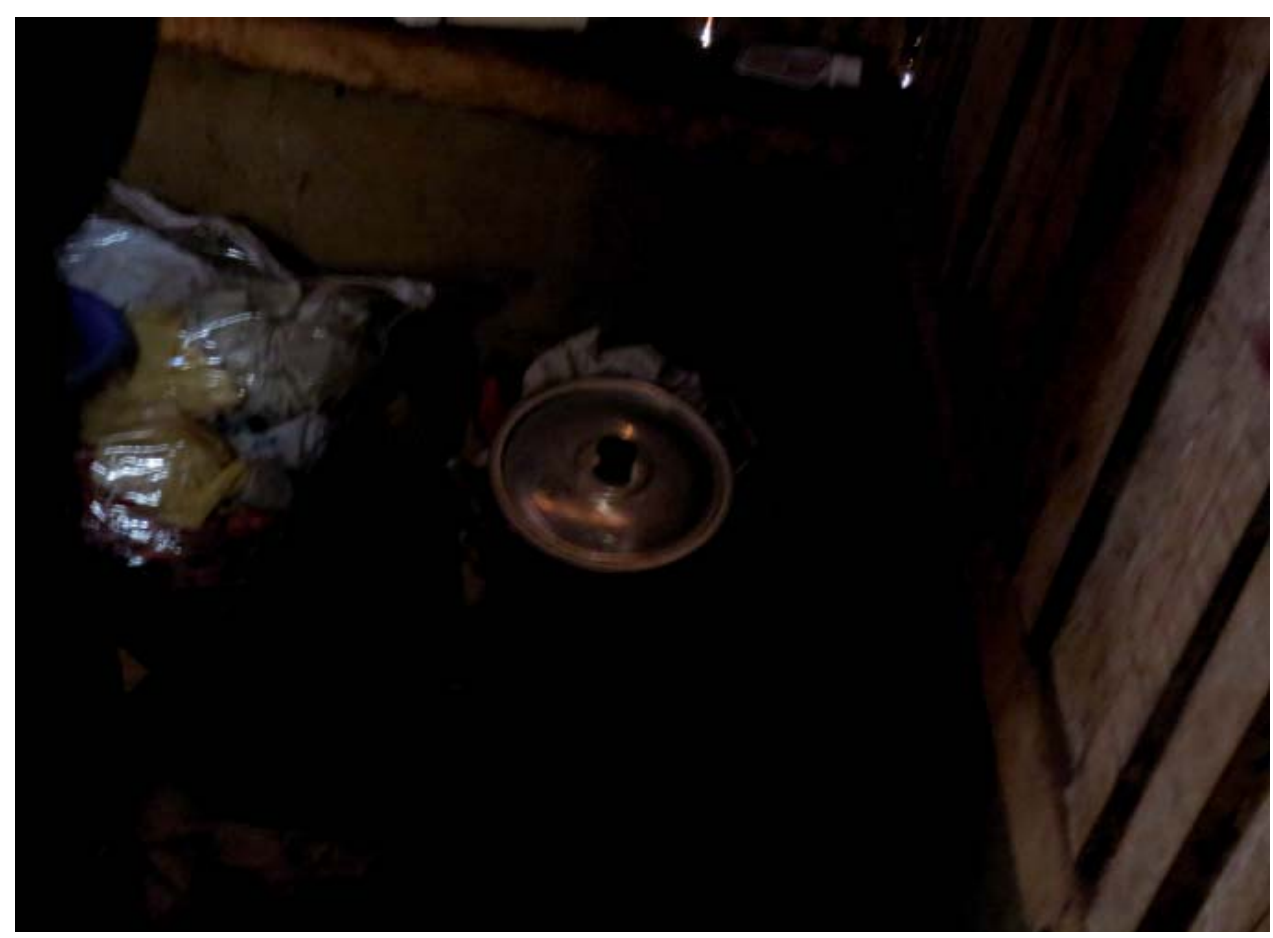

Foto 2- Reclusão, Panambizinho, novembro de 2014 (Lauriene Seraguza)

Os rituais dedicados ao sangue são recorrentes entre os povos ameríndios. Entre os Kaiowa e Guarani, o sangue (Tuguy) é percebido numa composição entre água ( $y$ ) e conhecimento ( $a r a n d u$ ), e, por isso, o sangue vertido precisa ser controlado para a produção da vida social. Verter o sangue incontrolavelmente é verter conhecimentos sem restrições e permitir que os acessem os humanos e outros seres sociais.

Luisa Elvira Belaunde aponta a existência de evidências etnográficas entre distintos ameríndios de que "o sangue é concebido como um fluido que corporifica e atribui gênero às pessoas, ao pensamento e à força, transportando conhecimento a todas as partes do corpo. O sangue opera tanto dentro do corpo de uma pessoa quanto fora dele" (BELAUNDE, 2006, p. 207). Para a antropóloga, verter sangue possui um "efeito transformador sobre a experiência vivida e abre as cortinas da comunicação e da percepção que geralmente separam a experiência cotidiana da experiência de outros tempos-espaços cosmológicos" (BELAUNDE, 2006, p. 208).

O sangue entre as mulheres kaiowa e guarani pode ser visto como uma marca ontológica da diferença entre homens e mulheres, anunciada desde o mito funda- 
dor desses coletivos (SERAGUZA, 2013). O sangue vertido na menstruação pode ser percebido como um resíduo da alteridade e, por isso, uma série de comportamentos devem ser adotados para minimizar essa condição de Outro, marcados na concepção da pessoa através da dualidade de sua alma e da "fabricação dos corpos" (SEEGER; DA MATTA; VIVEIROS DE CASTRO, 1979). O ritual que compreende a primeira menstruação, se trata de um momento de inconstância do corpo e da pessoa, e, por isso, exige procedimentos específicos dedicados à fabricação do corpo (rete) e à construção da pessoa (anga, ñe'e, ayvu) da mulher kaiowa e guarani.

Adriana Testa (2013), em sua tese de doutorado com os Mbya Guarani paulista, pensou a produção da corporalidade e da pessoa de modo articulado, seguindo a ideia de não opor corpos e pessoas, preconizada nas etnografias de Dominique Gallois (1988) entre os Wajãpi e a de Uirá Garcia (2010) entre os Awa Guaja. Testa pensa a pessoa como relação a partir da categoria de corpos-caminhos, em que estabelece uma conexão com a circulação dos saberes, a produção da pessoa, a alimentação com plantas e a produção do parentesco (TESTA, 2013, p. 242). Para Testa (2012, p. 168), o corpo seria "uma espécie de lugar passagem que concentra e por onde fluem as substâncias" e o eixo dos Guarani para a produção das pessoas.

Pode-se pensar que o corpo é o lugar da "perspectiva diferenciante [...] e pode ser visto como lugar de confrontação entre humanidade e animalidade" (VIVEIROS DE CASTRO, 2002, p. 388). Eduardo Viveiros de Castro (2002, p. 380) destaca que a diferenciação dos corpos se dá para além da fisiológica, "mas aos afetos, afecções ou capacidades que singularizam cada espécie de corpo: o que ele come, como se move, como se comunica, onde vive, se é gregário ou solitário". E resume: "Assim, a natureza humana é literalmente fabricada ou configurada pela cultura. O corpo é imaginado, em todos os sentidos possíveis da palavra, pela sociedade" (VIVEIROS DE CASTRO, 2002, p. 72).

\section{RITUAIS DE SANGUE}

Os rituais de fabricação corporal e construção da pessoa entre os Kaiowa e Guarani estão indissociavelmente imbricados, sendo impossível pensá-los com exclusividade. Esses rituais ocorrem nos momentos que, por verter sangue, em especial,

\footnotetext{
${ }^{6}$ Parte desta discussão está presente em minha dissertação de mestrado (SERAGUZA, 2013), mas aqui está apresentada com reelaborações que vem sendo construídas a partir do curso Redes e Relações Ameríndias.
} 
na menarca, no parto e no nascimento, são considerados como momentos de transformação corporal, ou, marcadores etários de mudança geracional, como no caso da menarca. Entre os Guarani Mbya, Valeria Macedo registrou que essas circunstâncias são percebidas como aquelas nas quais as relações sociais são reconfiguradas e o corpos singularizados (MACEDO, 2012, p. 187). Essas circunstâncias são apontadas por Schaden (1998) como momentos de "crise", ou, segundo Chamorro (1995), o tekoaku. Aku (MONTOYA, 2011, p. 28), em português refere-se ao calor, à sensação de estar quente que é associada ao que é bravo, ao violento e aos momentos de crise. Ouve-se entre os Kaiowa e Guarani também uma associação da categoria a uma condição de saraki, assanhado (VERA, 2017). Chamorro (1995, p. 103) o descreve da seguinte maneira:

Teko es el sistema guarani, su modo de ser. Aku es caliente. Tekoaku es, pues, um tiempo de crisis, de experiencia límite entre lo que se es y lo que se está por ser, o lo que se esta comezando a ser. Hay que respetar determinadas prescripciones para librarse de los peligros del modo de ser caliente y permanecer en el modo de ser frio (tekoro'y).

O Tekoaku pode ser pensado como um estado de devir, um momento de transição e transformação. Pode ser interpretado como necessário para as reflexões comportamentais daqueles que estão passando por esse estado, para que não fique pochy, bravo ou saraki, assanhado. Por isso a necessidade da reclusão; com ela, pode-se alcançar um estado de tekoro'y ou teko ro'y, um modo frio de se viver, com serenidade (CHAMORRO, 1995, p. 103), calmo, um modo de acordo com as condutas esperadas pelo coletivo que são apreendidas nesses momentos, que são considerados momentos para transmissão de conhecimentos específicos.

Ao aku ou haku também é atribuída uma ligação à feitiçaria que, para ser desfeita, deve-se esfriar- m'boroy ou mboro'y- o feitiço (MONTARDO, 2002, p. 169-70). Compreendi, a partir da vivência entre essas mulheres e homens, que o mboro'y, pode funcionar como um "contra-feitiço". Tekoaku é o modo de ser kaiowa quente, característica atribuída ao sangue, por isso a sua composição com a água, para esfriá-lo, buscando equilíbrio para a vida social. Segundo Schaden (1998, p. 101-2),

En la existencia del individuo, el nacimiento, la maduración biológica, las enfermedades, el nacimiento de los hijos y la muerte son los principales momentos de crisis. Para el grupo en su totalidad, situaciones especiales [...] ronpem de alguna forma el equilíbrio de la vida cotidiana y exigen o pueden exigir medidas rituales. No todas las situaciones de crisis requieren idênticas precauciones. Las más 
inportantes son aquellas em que la persona implicada recibe la designácion especial de (h)aku o odjéakú, estando sujeta al peligro de encantamiento sexual, a la que se denomina odjépotá. [...] El conjunto de las medidas que la persona debe tomar se llama "resguardo" em português; em guarani se dice simplemente que fulano está akú. Akú es el estado del padre (y entre los Mbüa también el de la madre) em los primeros dias después del nacimiento de la criatura, akú, es la jovem durante la primera menstruación y, finalmente (entre los Kayová) el niño em los dias que siguen a la perforación labial.

O tekoaku é um estado de desordem na vida das pessoas que o vivenciam, um estado de transição entre o "nós", pertencente ao grupo, e o "outro", estrangeiro ao coletivo. Na desordem, os seres sobrenaturais podem acessar os conhecimentos kaiowa e guarani e levar a pessoa a deslizar para condutas não aprovadas no coletivo; são levadas ao excesso, à superabundância produtora do Outro. Mary Douglas (1966) explora o estado ou estágio da "liminaridade" como imbricado ao clássico conceito de "ritos de passagem" de Van Gennep (2011). Para ela, o estado de liminaridade aponta para a desordem, mas mais do que isto, aponta para os "poderes" e para os "perigos" inerentes aos sujeitos nele imersos (DOUGLAS, 1966, p. 119).

Vivenciam o tekohaku, homens e mulheres, e nesses momentos, em que o resguardo, o batismo ou a perfuração labial com tembekua (entre os meninos) são percebidos como fundamentais para a produção e reprodução da vida social, são os momentos em que se incorporam - e, portanto, faz-se corpo, - os saberes. É preciso acúmulo de saberes para operar esses procedimentos rituais, como têm os ñanderu e ñandesy que acompanham essas situações, pois é preciso controlar o fluxo do sangue para manter o equilíbrio do corpo e pessoa, o que só podem fazer aqueles que possuem os saberes determinados para cada procedimento ritual. Não se pode verter sangue inadvertidamente; nem homens, nem mulheres.

Entre as mulheres, segundo Chamorro (2009), o sangue menstrual é uma substância que pode interferir na vida do coletivo, por isso a necessidade do resguardo:

Estando con su regla, la mujer debe quedarse quieta, ndaku'éi (T, 103), myne'ê (T, 107), napu'ãmi (T, 322), yvy rupi Aiko (V II, 172; T, 346). Esas frases, especialmente pochy - causa de muchos males y crisis en la cosmología indígena - pueden indicar la existencia, tambien en los grupos guarani, de uma regla o costumbre que apartaba la mujer de la vida cotidiana durante la menstruación, por miedo que sus fluidos interfiriesen negativamente con lo que era producido o se reproducía [...]. La voz "purgación" del castellano muestra el entendimiento de que al menstruar, la mujer expelía impurezas, se limpiaba [...]. (CHAMORRO, 2009, p. 178). 
Do fluxo do sangue aos cortes da vida em reserva: sangue, ritual e intervenção entre as mulheres Kaiowa e Guarani em MS

Chamorro o define como um operador de interferências negativas no que se produz ou reproduz. Geralmente é percebido como um perigo poluente, o sangue menstrual é apontado por Douglas (1966) como presente nos "estados de transição", isto porque "a transição não é nem um estado nem o seguinte, é indefinível. A pessoa que tem de passar de um a outro, está ela própria em perigo e emana a outros" (DOUGLAS, 1966, p. 119). Sendo assim, as mulheres menstruadas podem significar perigo para o coletivo étnico no qual estão inseridas, mas também, são detentoras de poderes, como assinala Simone Becker (2002) em sua etnografia sobre mulheres no Bairro das Flores, em SC. Becker sugere que sangrar é perigoso, mas pode também ser um modo de poder.

Observei entre as Kaiowa e Guarani que a mulher menstruada é proibida de tocar na plantação da roça, pois isso pode "estragar" ou "apodrecer a planta", prejudicando a alimentação da parentela, em qualquer menstruação, não necessariamente só na primeira. Estragar refere-se a apodrecer os alimentos e submeter à família extensa a ausência de determinados bens alimentícios da dieta kaiowa e guarani, cultivados nesses coletivos, em especial porque são elas as responsáveis por essa tarefa, o que pode ser percebido como um modo de poder. Entre os Piaroa, Overing (1999) registrou algo que sinaliza para essas reflexões, sobre o perigo das excreções corporais individuais para si e para o coletivo, a partir da percepção dos tabus alimentares seguidos nesses coletivos, em virtude da vulnerabilidade corporal:

Cada pessoa tem a responsabilidade de proteger os parentes, tanto quanto possível, dos perigos de suas próprias excreções corporais. Quando lida com aqueles muito jovens ou vulneráveis, um adulto tem de ser extremamente cuidadoso com o que come. Assim, tabus alimentares são obedecidos tanto em benefício de outros como de si próprio. (OVERING, 1999, p. 97).

Quando a menina kaiowa e guarani menstruar, já saberá dessas regras de convivência e poderá dar qualquer desculpa para se ausentar dos processos domésticos, pois será imediatamente compreendida, podendo justificar com uma dor de cabeça ou em sua evidente não disposição ao diálogo nesses momentos. Certa vez ouvi uma narrativa sobre um indígena que teve ciúmes da roça de outro indígena e, então, solicitou a uma mulher menstruada de sua parentela que passasse pelo meio da roça para prejudicar o receptor do ciúme, para "apodrecer a raiz e acabar com a roça, melancia, mandioca" e outros produtos alimentícios.

Durante esse estado, não era - e não é - permitido cozinhar, pois quem comer a comida pode correr risco de sentir dores viscerais, tais como as que as mulheres 
sentem durante esse período quando não realizam os procedimentos rituais adequados. Não é recomendável pelos mais velhos kaiowa e guarani que, durante esse período, as mulheres circulem por baixo de árvores frutíferas, pois o sangue vertido faz com que os frutos caiam e as raízes sequem. Principalmente quando se trata de pessoas estranhas à parentela do grupo. Soube da investida de um grupo de meninas em um pé de laranja e que, após o episódio, a árvore secou.

É possível sugerir uma aproximação sobre a afirmação de Belaunde de que "Essa vulnerabilidade da mulher menstruada é socialmente construída, ela faz com que a mulher se torne o lócus do cuidado dos outros" (DAINESE; SERAGUZA; BELAUNDE, 2016) para os cuidados rituais dedicados as mulheres kaiowa e guarani em suas primeiras menstruações, nos quais são tratadas com muito cuidado e afeto pelos membros da parentela. Também entre os Piaroa há um registro que possibilita uma analogia com os dados aqui apresentados. Overing (2006) aponta que o cerne do perigo da comida manipulada por um corpo que verte sangue se encontra na ingestão do "odor venenoso do seu sangramento", o que levaria as pessoas que degustassem da culinária à condição de doente:

Ao sangrar, sua vagina expele todos os venenos perigosos que ela havia internalizado durante o mês ao conviver com outras pessoas. O sangue menstrual é perigoso para os outros, especialmente para crianças e jovens, porque a mulher está se purificando profundamente, eliminando todos os pensamentos não domesticados emitidos pelos outros [...]. (OVERING, 2006, p. 46).

A antropóloga verifica o perigo de os jovens "ver, cheirar, tocar" ou qualquer outro tipo de "contato físico com o sangue menstrual", sob o risco de "morrer de alguma doença debilitante" (OVERING, 2006, p. 44). Entre os Kaiowa e Guarani do sul do MS, não se dorme junto, durante a menstruação. Caso ocorra, a pessoa padecerá de dores viscerais e males sobre-humanos, além da improdutividade no trabalho, no caso dos homens, devido a tais dores e males. Entre os Caxinauá, Yano ressalta a existência do resguardo nos momentos também percebidos como de vulnerabilidade e enumerados como pós-parto, menarca e doenças. Em relação ao pós-parto, Yano destaca que homens e mulheres só voltam a dormir juntos após o estancamento do sangue da mulher e a permanência firme, ereta e autônoma da criança (YANO, 2012, p. 206).

O período da primeira menstruação é reconhecido entre os Kaiowa e Guarani como um período ritual para a menina "tornar-se mulher" kaiowa e guarani. A menstruação possibilita a maturação do corpo e da pessoa, e pode ser pensada como um marcador etário para a vida a adulta. Entre os Caxinauás, Ana Yano registra que não 
Do fluxo do sangue aos cortes da vida em reserva: sangue, ritual e intervenção entre as mulheres Kaiowa e Guarani em MS

há um momento específico para que os homens e mulheres adultos tornem-se plenos e maduros, "o que parece decisivo [...] é o nascimento do primeiro neto (baba)" (YANO, 2012, p. 206). Para Schaden (1998) no resguardo é que se desenvolvem as habilidades manuais, próximo ao que ele chamou de "escola de economia doméstica", onde são reforçadas as condutas esperadas pelo coletivo por cada integrante, como forma de pertencimento e a partir da transmissão dos saberes dos mais conhecedores aos mais jovens.

Durante o resguardo, as regras para o pertencimento ao coletivo são apreendidas - de comportamentos, ritualísticas e alimentares -, como o cuidado da menina pelos membros da parentela, especificamente dos que coabitam com ela, como a mãe, a avó ou outro responsável. Essas regras incluem restrições alimentares, pintura corporal (jenipapo, uruku e cinza de cabaça queimada são os mais apontados), remédios e banhos com ervas (tipi, ysy, yary) do manuseio kaiowa e guarani, reclusão ao "fogo doméstico" (PEREIRA, 1999), além de aprender os ensinamentos ritualísticos, desenvolver habilidades na execução de tarefas no âmbito da convivialidade, como a costura, a limpeza da casa e a feitura de alimentos. Esses aprendizados foram relatados e vivenciados, em maior ou menor intensidade, pelas interlocutoras desta pesquisa, como parte desse ritual. São rituais nos quais os saberes circulam, se transformam e transformam os corpos e as pessoas que os vivenciam e os incorporam. Os saberes apreendidos durante os rituais transformam as pessoas em adultos disponíveis para as alianças.

Entre as Kaiowa e Guarani, estar haku não se trata de uma situação positiva, "é a pessoa, as meninas que procuram os homens, que ficam com qualquer um, porque não fizeram o resguardo". Qualquer um, inclusive ou principalmente, os seres não humanos. Haku, é a mulher que não sabe esperar o "tempo certo para estabelecer as relações sexuais", não se trata de ser exatamente o tempo em que está menstruada, pois, nesse momento, a mulher sente "dores, moleza no corpo e na cabeça", porque o sangue está "puxando para descer." Na reflexão que Belaunde traz sobre os postulados de Siskind, acerca dos Sharanahua, há uma proximidade com a condição vivida pelos Kaiowa e Guarani. Ele afirma que "al llegar la pubertad, los hombres y las mujeres llegan a la máxima potencialidad de sus sangres, por ló que están llenos de deseos de comery de tener sexo" (BELAUNDE, 2005, p. 64).

É possível vislumbrar outras maneiras para interpretar a etnografia dos Kaiowa e Guarani e pensar o haku e percebê-lo como um estado que comporta a potência da 
superabundância, da alteridade, o momento que permite a emergência do excesso na vida social Kaiowa e Guarani. Haku está relacionado com a teoria do gênero entre os Kaiowa e Guarani, segundo a qual os homens precisam se organizar de alguma forma para manter o controle entre as mulheres, o controle da alteridade radical instaurada por Mba'ekuaa e Aña desde os tempos míticos e percebida no excesso de sangue e de fala a partir da criação da mulher humana, com rabo, asas e chifres que foram minimizados pelo sopro humanizador de Pai Kuara, o criador do primeiro homem humano, o irmão mais velho dos gêmeos míticos (SERAGUZA, 2013). Mesmo assim, a mulher permaneceu com a marca da alteridade em que fora criada, cujos resíduos deste excesso de alteridade podem ser visualizados a cada lua nova, sua menstruação.

Aña foi circulado entre os Kaiowa e Guarani como o criador da primeira mulher humana. A criatura se assemelha ao criador nos excessos de diferença. Na literatura etnológica kaiowa e guarani, Aña adquire contornos de uma herança possivelmente cristã e pode ser encontrado em equivalência com o demônio, a personificação/divinização do mal instaurado por Mba'ekuaa (Aquele que Sabe) desde a primeira terra não humana. Mba'ekuaa e Aña remetem ao "Outro", um afim real ou um inimigo real, condicionante para a criação da vida social. O que eles tematizam é a distância social necessária para conduzir o sócius, uma alteridade radical ou a vida social. A alteridade oferece uma forma de integrar e um propósito de amarrar, de convergir e suas manifestações são percebidas a partir da socialidade com os humanos e outros seres sociais.

Entre as mulheres kaiowa e guarani, o ritual da primeira menstruação é acentuadamente dedicado ao corpo, inclusive ao sangue. O cheiro das moças nesse estado chama a atenção dos humanos e dos não humanos. Para evitar esse alvoroço cosmossocial, antigamente o resguardo durava dois meses, no período entre as duas primeiras menstruações, em meio ao qual raspavam a cabeça da menina, e a dieta alimentar era regulada até o crescimento dos cabelos. O controle desse período com ervas fétidas tem a eficácia de evitar a aproximação desses seres não humanos, pois as divindades são bonitas e cheirosas, e a menina haku não pode estar atrativa nesse período.

Os cortes de cabelos eram realizados para evitar os olhares alheios, e a reclusão preservava a menina dos perigos do mundo dos iniciados e transformava os seus corpos para esta nova condição: a de mulher, de corpo fértil, disponível para a reprodução da vida social, ou, nas palavras de Overing (1999) acerca dos Piaroa, "através da menstruação, vista como um processo de expulsão de forças femininas não domesticadas, a mulher torna-se poderosamente limpa, tornando-se propriamente fértil" (OVERING, 1999, p. 97). 
Do fluxo do sangue aos cortes da vida em reserva: sangue, ritual e intervenção entre as mulheres Kaiowa e Guarani em MS

Entre os Mbya do sul, Clarice Rocha Melo (2008) destaca que "Quando a menina atinge o período menstrual, deve-se fazer um resguardo, ficar mais em casa, fazer silêncio; corta-se o cabelo bem curto; não é recomendável que ela cozinhe ou prepare qualquer tipo de alimentos; não deve mexer com plantas, pois elas murcharão" (MELO, 2008, p. 91), recordando o caráter misterioso e questionável do sangue menstrual.

Deixar o sangue verter aos olhos, sem o resguardo, é aceitar a condição pochy que aguarda o "não iniciado". Para Belaunde (2005, p. 19), "la sangre entre los pueblos amazónicos reúne lo biológico, lo mental y lo espiritual”, pois, segundo a antropóloga, o sangue constitui as esferas da "fertilidade, saúde, trabalho, criatividade, bem estar, religiosidade, identidade pessoal e relações interétnicas" (BELAUNDE, 2005, p. 19). Entre os coletivos estudados, a diferença não se faz gradativa.

A dieta alimentar nesses processos ritualísticos entre os Kaiowa e Guarani se concentra nos peixes e nos grãos; destacam que proporcionam limpeza ao corpo e disfarçam a mortalidade e a alteridade, veiculada pelo sangue, a que estão submetidas as mulheres kaiowa e guarani. O peixe é um alimento reconhecidamente dotado de potência positiva entre os Kaiowa; diz-se que é uma comida fria, mboro'y, sua agência é contrária ao que propõe Viveiros de Castro (2002) para este alimento entre os Yawalapíti, forte veiculador de alteridade.

Ao fim do tekoaku as mulheres estariam "fortalecidas". Na atualidade, observo que essas práticas permanecem presentes, apesar de realocadas no cotidiano. As mulheres evitam excessos (trabalhos árduos, passeios, comidas "fortes"), conversas aleatórias e excesso de exposição durante as "regras" e, ao fim destas, elas entram no estado tekoro'y, de mansidão, esfriamento, em que as restrições são revistas (SERAGUZA, 2013). O cheiro do sangue menstrual adverte aos seres sobrenaturais que aí se encontra um corpo suscetível, haku, que precisa ser esfriado, mboro'y, disfarçado, protegido com as rezas/cantos, as ervas, os banhos, a reclusão da vida social, os interditos alimentares, principalmente no tocante às carnes de caça. $\mathrm{O}$ historiador Kaiowa Izaque João (2011) sublinha que os tabus alimentares relacionados às carnes de caça são necessários, pois possuem coeficientes que potencializam a desordem na vida social, se consumidos durante o período de vulnerabilidade do corpo, os que assolam as mulheres, como a menstruação e a gravidez:

Na concepção kaiowá, diversas características de doenças são provocadas pela má exploração dos recursos naturais. A carne de animais silvestres também causa doença por meio de ojepota (incorporação de um espírito), especialmente 
quando a mulher está em período de gestação. Algumas carnes ingeridas pela gestante são extremamente perigosas para a criança. Para não correr esse risco, as mulheres devem seguir as orientações dos xamãs, pois podem adquirir doenças transmitidas pela carne de animais de caça. Isso afeta também as moças em período de menstruação, pois, se desrespeitarem a regra, após o parto da criança, pode ocorrer complicações. [...] Cada animal, no conhecimento kaiowá, possui sua regra de consumo para ambos os sexos. Um exemplo é a capivara, animal que habita em várzeas, beira de córregos, rios ou açudes. Quando é perseguida pelo caçador ou por outro animal carnívoro, para fugir do perigo ele cai na água e fica um bom tempo imerso e somente após alguns minutos retira da água a ponta do nariz para respirar. Segundo as informações dos xamãs, no período de lua nova, este animal não cai na água, porque esta é vista por ele como sangue. Por este motivo, a carne de capivara se torna muito perigosa para as mulheres kaiowá, devido ao ciclo de menstruação, que ocorre na fase de lua nova, causando excesso de fluxo menstrual. O consumo de carne de animal de caça pelo Kaiowá define o seu bem estar na conduta pessoal. No entanto, é preciso seguir as regras específicas para não provocar a irritação do dono de animal (so'o jára). (JOÃO, 2011, p. 39-40).

Ouvi em campo que a carne de caça tem um "cheiro forte", sugerindo sedução e, assim, pode gerar perigo e, de certa maneira, poder às mulheres. A possiblidade de doenças nesses momentos de sangue vertido e de circulação excessiva e concentrada de sangue, nos remete às elaborações de Macedo acerca dos Guarani Mbya, quando afirma que "Diferente dos brancos, no corpo dos Guarani tudo não é normal [...] a pessoa se constitui assim como uma rede de afetos e afeç̧ões, experimentando posições de sujeito e de sujeitado a desejos e efeitos de outros corpos, dentro e fora de seu próprio corpo" (MACEDO, 2012, p. 187).

Mas, e quando o Estado ignora os saberes indígenas, os seus modos de circulação e transformação e faz das reservas indígenas, como no caso da de Dourados, MS, uma extensão dos bairros periféricos da cidade, oferecendo uma gama de equipamentos públicos que não levam em consideração os valores e as configurações sociocosmológicas do coletivo? Seria a reserva, um corte na rede de circulação e transformação de saberes?

\section{OS CORTES DA VIDA EM RESERVA}

Se o sangue é composto por conhecimento, ele pode ter o fluxo cortado quando a vida é em Reserva. A proximidade das casas, o amontado de pessoas em poucos hectares de terra, a escassez de mata, rios e a obrigatoriedade do convívio coletivo entre kaiowa, guarani e terena, etnias que compõem o cenário multiétnico da reserva 
de Dourados, geram uma série de processos de desarticulação interna que cortam o fluxo do parentesco, da solidariedade e do ritual. Sendo assim, como controlar os olhares durante o resguardo, acessar os remédios e evitar o alvoroço cosmossocial causado pela presença das três etnias durante os procedimentos rituais? Não é de se espantar que a alternativa religiosa, em especial as igrejas neopentecostais, seja amplamente aceita nas reservas do MS e reúna participantes das três etnias.

Se a menstruação pode ser percebida como um "marcador etário" do momento em que se torna mulher, adulta, estando apta a compor o seu próprio "fogo doméstico", pode ser percebida então como o momento de maturação plena da mulher, o que a habilita a realização de alianças. Mas como explicar isto ao Estado, que impõe a idade liame de 16 anos para um "relacionamento consentido" entre homens e mulheres, independente da realização dos rituais e da própria autonomia na organização social indígena, e tem livre acesso às reservas, causando transformações estruturais na vida dos índios?

As mulheres indígenas são parte componente dessas transformações estruturais. Enquanto Schaden (1998) sublinhou, no século passado, a cultura guarani como "marcadamente masculina", Pereira (2008) afirmou, no presente século, que os homens kaiowa são "condenados à dependência" do "fogo doméstico" controlado pelas mulheres. Entre os Guarani, refere-se à mulher da casa como che ra taipy jara, a dona do fogo. As mulheres casadas lideram o controle do "fogo doméstico", principalmente a partir da prerrogativa contida no poder de "nutrir" o grupo familiar. Pressupõe-se que quem nutre possui um conhecimento acumulado, como a maturidade expressada por um tamoi e uma jari, um casal de avós e por isso, possuem autoridade para transmitir os saberes.

Etnografias como a de Schaden (1998), realizada no início do século XX, apontam para a cultura guarani, de maneira geral, como masculina e uxorilocal (o matrimônio pressupõe a vinda do genro para a casa do sogro). Pereira afirma que o homem é o "articulador da parentela" (PEREIRA, 2004), sendo esta extensa e composta por parentes consanguíneos e afins. Entretanto a parentela é dependente da existência do "fogo familiar", que está sob a égide da mulher casada, da esposa, da mãe - preferencialmente gorda, forte e sábia (PEREIRA, 2004). Pereira (2004) sublinha que a uxorilocalidade é uma política de produção da parentela e da sociedade, em que o casal (pai e mãe) e filhas significam mais genros.

O casal é portador de prestígio perante o grupo, é uma herança cósmica, do Primeiro Pai e da Primeira Mãe, e aos Kaiowa e Guarani, é uma obrigação seguir e 
"imitar" o exemplo dos deuses, no caso, formando um casal. A conjugalidade, como um modo ideal datado dos tempos míticos, é bastante apreciada entre esses indígenas, assim como, a composição de um "fogo doméstico" formado preferencialmente por um casal, o que sublinha a necessidade da complementariedade nas relações sociais estabelecidas. Entre os Mbya, Elizabeth Pissolato (2012, p. 99) afirma que "a figura do casal parece ocupar um lugar privilegiado, por ser o lugar por excelência da definição de habilidades distintas - generizadas -, que se põem em relação e se complementam na produção e reprodução da vida social".

A conjugalidade adquire grande importância na vida social dos Kaiowa e Guarani. Este é o fator que dá pertencimento a um fogo, para o Kaiowa; por isso que aos solteiros é atribuída a necessidade de aquisição de matrimônio para evitar uma "ruína da vida social" (PEREIRA, 2004, p. 60). Um homem sem uma mulher, e vice e versa, acaba por cometer deslizes sociais pouco aceitáveis, podendo até tornar-se antissocial, aos moldes de Aña, principalmente no tocante à economia doméstica, ao uso e controle do dinheiro ganho para a compra de produtos manufaturados de consumo no "fogo doméstico".

Em minha breve atuação como assistente na FUNAI (2014-2015), na Regional de Dourados, uma das pautas que acompanhei foi a de violações de direitos de crianças e jovens indígenas. Nesse contexto, acompanhei um caso de uma menina que foi "doada" para uma família criar, ainda bebê, porque os genitores afirmavam que ela era bicho, e não poderiam cuidar. O ser bicho foi identificado por conta da presença de um "rabo" nessa criança. Ela foi criada por outra família, não consanguínea na RID, como guacho, filha adotiva, e, após a sua menarca, se casou com o filho da "mãe adotiva", este, já com mais de cinquenta anos, e esta com 14. Ela engravidou.

Durante a pesquisa de campo para o mestrado, ouvi diversas vezes que "As crianças nascem com rabo, é preciso rezar para cortar". Esse aspecto da animalidade, que resiste nas crianças, enquanto não pessoas e, de certa maneira, não humanos, até que se realize o batismo, é a herança estética deixada por Aña às mulheres: os seus filhos são fabricados a partir dos excessos da primeira mulher e detêm dela um de seus primeiros atributos, o rabo.

A reza, o sopro que sai da boca em formato de canto, é portador de humanidade e possibilita a sua circulação por dentre os corpos das crianças, minimizando a condição de alteridade herdada das mulheres. Mas há crianças que crescem com rabo, e cortá-lo refere-se à concordância e ao pertencimento às regras da vida social dos Kaiowa e Guarani, sugerindo, também, outras modalidades de transformação nos corpos. 
Do fluxo do sangue aos cortes da vida em reserva: sangue, ritual e intervenção entre as mulheres Kaiowa e Guarani em MS

O rabo é um resíduo da alteridade absoluta das mulheres; cortar o rabo adquire os mesmos efeitos do sopro de Pa'i Kuara na primeira mulher humana, possibilitando a existência de um "oposto equivalente assimétrico" (PEREIRA, 2008; SERAGUZA, 2013) entre os gêneros e minimizando a sua "superabundância ontológica" (VIVEIROS DE CASTRO, 2002). "Cortar o rabo" evidencia, entre os Kaiowa e Guarani, uma perspectiva de continuidade da relação com os divinos, pois cortar o rabo, através da reza/canto, é um procedimento ritual divino necessário para seguir os preceitos fundamentais da organização social kaiowa e guarani.

Quando, durante a internação em virtude da gestação, ventilou-se no hospital que a menina internada era casada com um homem de mais de cinquenta anos, que a visitava semanalmente na internação, o conselho tutelar foi acionado e retirou a menina do convívio familiar, por afirmar que havia ocorrido um estupro de vulnerável, mesmo com a afirmativa da menina em relação à situação de conjugalidade que ela vivia com o homem, e a afirmativa do homem sobre a relação mantida com ela. Ainda assim, o Conselho Tutelar não permitiu que eles voltassem a conviver, mesmo com a intervenção da FUNAI pró casal.

A vida em reserva é marcada por tensionamentos. Para os Kaiowa e Guarani, após o ritual da primeira menstruação, a menina já está apta para contrair o matrimônio, mas isto ocorre de maneiras diferentes entre a vida em Reserva e a terra indígena recuperada. Na terra indígena, tem um controle interno das problemáticas maior, o que se difere da reserva, onde esses problemas escorrem pelas brechas dessa invenção do Estado que interfere e condiciona o modo de vida desses indígenas e os obrigam ao diálogo com as agências do Estado, que pouco se esforçam para compreender e respeitar a autonomia desses povos, já garantidas na Constituição Federal e reforçada com a 169 da Organização Internacional do Trabalho (OIT). E assim, os pune por não compartilhar da lógica não indígena, como esse caso da menina que, após a menstruação, se disse casada, e foi negado a ela o seu direito de ser.

Em outro momento, acompanhei um caso de acolhimento arbitrário de cinco crianças da terra indígena de Panambizinho, com a acusação de que estavam em estado de vulnerabilidade por conta do pai e mãe vivenciarem uma situação alcoolista. Quando fui conversar com a família, a maior preocupação era que uma das meninas, estava em vias de menstruar pela primeira vez e, portanto, já estava com a dieta regulada. A preocupação era: "e se ela menstruar, longe de casa?". Por sorte, e por atuação da equipe da FUNAl e uma forte mobilização da parentela, as crianças foram desacolhidas em uma semana e puderam voltar ao convívio familiar. 
A mobilização da parentela nesse caso só foi possível por não se tratar de uma família de Reserva: moram lado a lado, entre parentes, exercem práticas de solidariedade mútua e mantêm muito de seus modos próprios de resolução de problemas. Em Panambizinho, a preocupação com os rituais é latente: talvez seja a forma de agradar os Jara, os donos, e reestabelecer a vida plena no tekoha reconquistado há pouco mais de dez anos. Com os parentes mobilizados, em solidariedade, a defesa da parentela é possível frente às arbitrariedades do Estado. Diferente da vida em reserva, onde o estatuto geracional, pós-menarca, circulado pelo sangue foi questionado pelo Estado, à revelia do discurso dos envolvidos. Isto reitera a ideia dos modos distintos de vida, e circulação e transformação de saberes, na reserva, e na terra indígena recuperada.

Dessa forma, é possível "levar a sério" (VIVEIROS DE CASTRO, 2002) os rituais dedicados ao sangue como "marcadores etários" (LÉVI-STRAUSS, 2010), e o próprio sangue como circulador e transformador dos conhecimentos nos corpos e nas pessoas Kaiowa e Guarani, em especial das mulheres, em contraste com o Estado uniformizante, que intervém nas relações mais sutis e insiste em tratar os índios, como pobres em geral.

\section{CONSIDERAÇÕES FINAIS}

O desafio em expor experiências que afirmam uma certa atualização da "tradição", se agrega ao desafio na escrita de transmitir o meu olhar como etnógrafa e como indigenista da FUNAI à época. Parto da prerrogativa de que a etnografia como método é permeável para a entrada de outros conhecimentos.

As reflexões sobre o controle do sangue, sobre a rejeição da quentura nos modos de vida Kaiowa e Guarani sugerem que estas desencadeiam processos de transformação que vão ao encontro de modos de vida muito intensos que extrapolam, gerando o que Schaden (1998) chamou de estados de crise, ou o Tekohaku aqui problematizado. Nessas condições, o sangue menstrual, marcador do tekohaku, é aqui pensado a partir de suas consequências cosmológicas e de seus afetos provocados.

Outros momentos do tekohaku são muito instrutivos para perceber esse momento de crise. A intensidade dos cuidados, da observação desses cuidados nesse período ocorre muito em função das diferenciações sociais que existem entre as próprias famílias, sempre se observa ao menos uma coisa durante esses rituais. A intensidade da coisa observada, a intensidade do cuidado vai ao encontro da expec- 
tativa da família em relação à norma, importante para diferenciação social. Não está relacionado somente na vida em reserva, pois os dados históricos e etnográficos da região apontam que isto sempre existiu, contrariando a percepção do ymaguare, o tempo antigo, como ideal, por ter o tipo de vida social mais associado à prática. Isto traz para o centro das preocupações a necessidade de etnografias sensíveis para a heterogeneidade nas famílias e suas séries de práticas relacionadas, e que, de fato, nem sempre foi bem assim. Não se trata somente de etnografar, mas importa extrair dessas diferenciações as implicações que isto tem para a vida social.

Em muitos casos, os processos de desarticulação interna promovidos pelo Estado, seja na reserva ou na terra indígena recuperada, resultam em violências múltiplas que são conectadas pelas pessoas kaiowa e guarani em geral como a ausência dos procedimentos rituais durante o tekohaku. Em conversa com o historiador kaiowa Izaque João, ele afirmou que o resguardo da mulher existe como parte de um processo para a vida futura para obter o bem-estar, para a concepção de crianças, para a vida adulta e para manter-se em bom estado de saúde, para um envelhecimento manso, como deve ocorrer entre os Kaiowa e Guarani.

Isto sugere uma atualização da relação da violência, estupros cometidos por indígenas, suicídios entre os indígenas com a ausência de procedimentos rituais entre as mulheres e entre os homens da realização do ritual do kunumi pepy, que coloca o tembekua nos meninos através de perfuração labial. Entretanto, mesmo os rituais não ocorrendo com a mesma intensidade, há outras formas atuais para transmitir e circular esses conhecimentos. Sem acessar tais saberes, sem o controle do fluxo do sangue, a pessoa fica vulnerável à ação dos humanos, do Estado e de outros seres sociais, a cometer atitudes violentas na vida e nas sociedades por onde circulam.

Os conhecimentos mobilizados nesses rituais de controle do sangue estão conectados às redes de relações que compõem corpos e pessoas entre os Kaiowa e Guarani e ativam modos de circulação, de transformação de saberes que se realizam no corpo, feixe de relações e de transformações na vida ameríndia. Mas esses conhecimentos e sua circulação dependem das condições disponíveis para se viver, o que se agrava vertiginosamente com o desrespeito por sua organização social, cosmológica, seus modos de criar as crianças, a falta de terra, o confinamento nas reservas e os despejos de terra violentos; todos organizados pelo Estado. 


\section{REFERÊNCIAS}

AQUINO, Tânia Fátima. Mitã kunha ikoty ñemondy'a: o ritual da menarca no contexto escolar kaiowa da aldeia panambizinho em Dourados, MS. 2017. Trabalho de Conclusão de Curso (Licenciatura Intercultural Indígena) - Universidade Federal da Grande Dourados (UFGD), Dourados, MS, 2017.

BELAUNDE, Luisa Elvira. A força dos pensamentos, o fedor do sangue. Hematologia e gênero na Amazônia. Revista de Antropologia, São Paulo, v. 49, n. 1, p. 205-43, jan./jun. 2006.

. El recuerdo de la luna. Género, sangre y memoria entre los pueblos amazónicos. Lima: Fondo Editorial de la Facultad de Ciencias Sociales, Unidade de Pos Grados de Ciencias Sociales, 2005.

BECKER, Simone. Honras \& estratégias: formas de ser mulher no bairro das Flores. 2002. Dissertação (Mestrado em Antropologia Social) - Universidade Federal do Paraná (UFPR), Curitiba, PR, 2002.

CAPIBERIBE, A. Não cutuque a cultura com vara curta: os Palikur e o projeto "Ponte entre povos". In: CUNHA, M. C. da; CESARINO, P. de N. (Org.). Políticas culturais e povos indígenas. São Paulo: Cultura Acadêmica, 2015. Cap. 6, p. 165-90.

CHAMORRO, Cândida G. A. Terra madura, yvy araguyje: fundamento da palavra guarani. Dourados, MS: Ed. UFGD, 2009.

. Kurusu Ñe'ëngatu: palavras que la história no podría olvidar. Assunción: Centro de Estúdios Antropológicos/Instituto Ecumênico de Posgrado/COMIN, 1995.

DAINESE, Graziele; SERAGUZA, Lauriene, BELAUNE, Luisa Elvira Sobre gêneros, arte, sexualidade e a falibilidade destes e de outros conceitos: Entrevista com Luisa Elvira Belaunde Olschewski. Revista Ñanduty, Dourados, MS, v. 4, n. 5, p. 286-307, 2016.

DOUGLAS, Mary. Pureza e perigo. São Paulo: Perspectiva, 1966.

FUNDAÇÃO NACIONAL DO ÍNDIO (FUNAI). Relatório Geral Sobre Área Indígena Guarani PaiKaiowa do Rio Iguatemi - MS. Brasília, 1984. 38p.

GALLOIS, Dominique. O movimento na cosmologia waiãpi: criação, expansão e transformação do universo. Tese (Doutorado em Antropologia) - Universidade de São Paulo (USP), São Paulo, 1988.

GARCIA, Uirá Felippe. Karawara. A caça e o mundo dos Awá-Guajá. 2010. Tese (Doutorado em Antropologia Social) - Universidade de São Paulo (USP), São Paulo, 2010.

GENNEP, A. V. Os ritos de passagem. 2. ed. Tradução de Mariano Ferreira. Petrópolis, RJ: Vozes, 2011

JOÃO, Izaque. Jakaira Reko Nheypyrũ Marangatu Mborahéi: origem e fundamentos do canto ritual jerosy puku entre os Kaiowá de Panambi, Panambizinho e Sucuri'y, Mato Grosso do 
Do fluxo do sangue aos cortes da vida em reserva: sangue, ritual e intervenção entre as mulheres Kaiowa e Guarani em MS

Sul. 2011. Dissertação (Mestrado em História) - Universidade Federal da Grande Dourados (UFGD), Dourados, MS, 2011.

LÉVI-STRAUSS, Claude. Suplício do Papai Noel. São Paulo: Cosac Nayf, 2010.

LOPES, Adelia Flores. O sangue entre as mulheres Guarani e kaiowa em Amambai. 2016. Trabalho de Conclusão de Curso (Licenciatura em Ciências Sociais) - Universidade Estadual de Mato Grosso do Sul (UEMS), Dourados, MS, 2016.

MACEDO, Valeria. Jepota entre os Guarani. Tramas de quereres e corpos. Relatório PT. Redes Ameríndias, 2012.

MELIÀ, Bartomeu; GRÜNBERG, Georg; GRÜNBERG, Friedl. Los Pãi-Tavyterã-Etnografia Guarani del Paraguay contemporáneo. Asunción: Centro de Estudios Antropologicos. Universidad Católica “N. S. de la Asunción”, 1995.

MELO, Clarice Rocha de. Corpos que falam em silêncio - escola, corpo e tempo entre os Guarani. 2008. 146p. Dissertação (Mestrado em Antropologia Social) - Universidade Federal de Santa Catarina (UFSC) Florianópolis, SC, 2008.

MONTARDO, Deise Lucy Oliveira. Através do M’baraká: música e xamanismo guarani. 2002. 276p. Tese (Doutorado em Antropologia) - Universidade de São Paulo (USP), São Paulo, 2002.

MONTOYA, Antonio Ruiz de. Tesoro de la Lengua Guaraní. 1. ed. Apresentação de Bartomeu Meliá. Assunção, Paraguai: CEPAG, 2011.

OVERING, Joanna. O fétido odor da morte e os aromas da vida. Poética dos saberes e processo sensorial entre os Piaroa da Bacia do Orinoco. Revista de Antropologia, São Paulo, v. 49, n. 1, p. 19-54, jan./jun. 2006.

. Elogio do cotidiano: a confiança e a arte da vida social em uma comunidade amazônica. Revista MANA, v. 5, n. 1, p. 81-107, 1999.

PEREIRA, Levi M. A socialidade da família Kaiowa: relações geracionais e de gênero no microcosmo da vida social. Temáticas. Revista dos pós-graduandos em Ciências Sociais IFCH, Campinas, SP, ano 16, n. 31/32, 2008.

PEREIRA, Levi M. Imagens Kaiowá do sistema social e seu entorno. 2004. 403p. Tese (Doutorado em Antropologia Social) - Universidade de São Paulo (USP), São Paulo, SP, 2004.

PEREIRA, Levi M. Parentesco e organização social Kaiowá. 1999. 251p. Dissertação (Mestrado em Antropologia Social) - Universidade Estadual de Campinas (UNICAMP), Campinas, SP, 1999.

PISSOLATO, Elizabeth. Gênero, casamento e trocas com brancos. In: SACCHI, Angela; GRAMKOW, Marcia (Org.). Gênero em povos indígenas. 1. ed. Rio de Janeiro/Brasília: Museu do Índio, 2012. v. 1, p. 33-52. 
SCHADEN, Egon. Aspectos fundamentales de la Cultura Guaraní. Assunción: Universidad Católica, 1998.

SERAGUZA, Lauriene. Cosmos, corpos e mulheres Kaiowa e Guarani. De Aña a Kuña. 2013. 196p. Dissertação (Mestrado em Antropologia) - Universidade Federal da Grande Dourados (UFGD), Dourados, MS, 2013.

SEEGER, A.; DA MATTA, R.; VIVEIROS DE CASTRO, E. B. A Fabricação dos corpos nas sociedades indígenas no Brasil. Boletim do Museu Nacional, Rio de Janeiro, n. 32, maio 1979.

TESTA, Adriana. Caminhos e saberes Guarani-Mbyá: modos de criar, crescer e comunicar. 2014. Tese (Doutorado em Antropologia Social) - PPGAS/Universidade de São Paulo (USP), São Paulo, 2014.

. Caminhos de criação e circulação de saberes. Relatório Científico PT. Redes Ameríndias, 2012.

VERA, Kelly Duarte. Conhecimentos, práticas e rituais envolvidos na preparação das meninas guarani e kaiowa para o teko porã. 2017. Trabalho de Conclusão de Curso (Licenciatura Intercultural Indígena) - Universidade Federal da Grande Dourados (UFGD), Dourados, MS, 2017.

VIVEIROS DE CASTRO, Eduardo. A inconstância da alma selvagem - e outros ensaios de antropologia. São Paulo: Cosac \& Naify, 2002.

YANO, A. Tie. Saber-ser: corpo, pessoa e conhecimento entre os Caxinauas. Relatório PT. Redes Ameríndias, 2012.

\section{Sobre a autora:}

Lauriene Seraguza: Possui graduação em Letras Licenciatura com habilitação em Português-Inglês pela UFMS (2005)/UFGD(2006). Mestre em Antropologia Sociocultural pela UFGD/PPGAnt (2013), na linha de pesquisa em Etnologia Indígena. Doutoranda em Antropologia Social no PPGAS/USP. Atua nas áreas de Etnologia Indígena, com ênfase nas temáticas de organização social, parentesco, transformações e cosmologias ameríndias e gênero entre os Kaiowa e Guarani em MS. E-mail: seraguzza@gmail.com

Recebido em 8 de janeiro de 2017 Aprovado para publicação em 18 de abril 2017 